Technical Note

\title{
Documenting the Heritage of Nokia-From Discussions to Catalogue
}

\author{
Emilia Västi \\ Museum of Technology, Viikintie 1, 00560 Helsinki, Finland; emilia.vasti@tekniikanmuseo.fi
}

Received: 14 December 2018; Accepted: 9 February 2019; Published: 12 February 2019

check for updates

\begin{abstract}
In 2015, the Museum of Technology received a donation of ninety data communication devices from the 1960s to 2010s, collected and arranged by employees of the Nokia Data Communications department. The museum has been organizing (2018-2019) documentation workshops to collect information and connect individual objects with larger concepts such as company history, innovations, and technologies. The idea is to gain comprehensive contextual information about the collection by bringing together expertise and experiences of (former) Nokia employees, and documentation and interpretation skills of museum professionals. The method of the documentation workshops is a conversational interview inspired by the objects. Subsequently, workshop discussions were planned to be digested and used in cataloguing individual objects and object groups by museum professionals. Eventually significance assessment was chosen as a tool for summarizing the documentation project. The paper discusses the planning and organizing of the outcomes of the documentation workshops and asks the following questions: What is the optimal relationship between cataloguing information in the collections management system and documentation of workshop discussions preserved in the museum's collection archive? How should the workshop be documented to trace the provenance of the information? What information should and can be collected on the workshop participants?
\end{abstract}

Keywords: documentation; Nokia data communications collection; significance assessment; photo elicitation; museum collections

\section{Introduction}

In context of museum collections, "Heritage of Nokia" may easily evoke thoughts of collecting mobile phones. However, this case study discusses museum documentation of a product line less known. The devices at the Nokia Data Communications Collection of Museum of Technology are mostly modems. They have served out of sight, for example, in automated teller machines, decades before the landline modems became common in households providing the chance to "surf the web". Therefore, these devices have long been an indispensable part of telecommunications and from the perspective of a Finnish museum, they can also be studied as a part of the story of Nokia companies. The ongoing documentation workshops organized by the museum have shown, that for their developers, the modems are an excellent starting point for discussions and also a stimulus to evoke personal memories. But, how about other museum visitors? Statements like, "I'm not very skilled in these technical matters" and "Boring ( . . ) mass production, anonymous ( ... )" were expected to some extent when a simple survey was arranged in the entrance lobby of the museum, inviting visitors to share their thoughts on two example devices. One of the goals of the documentation project discussed in this paper is to help narrow the gap between the distinct reactions described. The project can be addressed as field research, the field being the museum collection, bringing together museum professionals, Nokia engineers, and museum visitors. The essential aim is to gather and preserve modem-related memories and knowledge of former employees of Nokia Data Communications in the 
workshops. In this paper, "Nokia Data Communications" refers to all phases of the Nokia modems department, regardless of changes in company structure and official names of the business unit that changed several times. The business that involves modem devices is now a part of spin-off company, Dedicated Network Partners DNWP, which was founded in 2011. "Nokia Data Communications collection" of the Museum of Technology represents all eras of Nokia-related modems, including some models of DNWP.

In this paper, I discuss the planning of the documentation project, in particular, the views on optimal relation between cataloguing information in a collections management system and documentation of the workshops in a collection archive. In the following chapter, I introduce briefly the collection in discussion. In chapters three and four, I discuss preliminary plans regarding the workshop discussions in relation to cataloguing objects and why we chose significance assessment [1,2] as a tool and outcome of the documentation. In chapter five, I talk about the practical implementation of the workshops and also explain the applied use of the photo elicitation method [3,4]. In chapter six, I present the conclusions. The workshops were ongoing at the time of writing of this paper (summer of 2018). The assessment will continue until the spring of 2019; the Statement of Significance of the collection is not included in this paper.

\section{How "Museum of Modems" Became Nokia Data Communications Collection}

The Museum of Technology is maintained by a foundation and celebrates its 50th anniversary in 2019. It is the only professionally managed general museum of technology in Finland. The current collection mission follows the aim to represent the story of the role of technology and industry in Finland, from when it was an agrarian society to becoming a leading developer and producer of high tech in the global market. Among all objects, the museum collections contain approximately 50,000 artefacts that can be divided into 34 sub-collections. This number includes collections formed by themes and provenance.

The starting point of the documentation project is one of the sub-collections, "Nokia Data Communications". It is non-accumulating collection based on a single donation in 2015. The collection consists of less than a hundred artefacts. It is, therefore, small in quantity, but covers six decades of development and production of data communication devices by Nokia from the 1960s to the 2010s. The collection does not contain every model produced, but according to workshop participants, all the central phases of product development are presented. The process that led to the donation in 2015 began when a long-term employee of Nokia contacted the collection department at the Museum of Technology. Concern for the preservation of the collection was present. The official owner of the modem collection at this stage was a network company, Dedicated Network Partners DNWP. It is a spin-off company of Nokia, but a connection between the two, hence the name, is no longer evident.

The set of modems was considered to be a "musealic" collection even before the devices were accessioned into collections of the Museum of Technology. Collectors of the devices (i.e., the people who have worked for the Nokia Data Communications) had named it "museum of modems" and Nokia Data Communications customer magazine unveils the origins of the collection to be in late 1980s [5]. According to a former Nokia employee, the "museum of modems" was relocated a couple of times following the staff to new premises and had witnessed several rearrangements in organization. Even the logos on the devices tell a story of change: Nokia Electronics, Nokia, Nokia Siemens Networks, DNWP... When the collection was at the DNWP premises, previously used by Nokia Siemens Networks, the modems were placed in open office and arranged on a bookcase behind a glass wall, resembling a museum display case. This level of significance was considered interesting and it was one of the reasons why the museum chose to accept the whole collection and decided to manage it as a separate sub-collection. An alternative would have meant choosing only some of the devices to complement the existing collection of Communications and Media that already had some Nokia modems.

From the beginning of the process, there was an intention to continue collaborating with persons that were centrally involved in the donation, for example, in cataloguing the collection. And soon after 
the donation, a group of twenty people taking part in a Nokia Data Communications reunion visited the museum and wished to see the collection that was temporarily housed in the collections workspace. Enthusiastic chatter during the visit indicated that an even-larger group might be interested in being involved in the documentation work. However, the small team working in the collections department of the museum was occupied with other projects for the next couple of years.

\section{Preliminary Project Plans-What to Do, with Who and How?}

According to the ICOM Code of Ethics for Museums, museum collections should be "documented including full identification and description of each item, its associations, provenance, condition, treatment and present location" [6] (p. 14). This is an essential part of care of collections and commonly designated to cataloguing the museum objects. When the documentation project of Nokia Data Communications collection started in the spring of 2018, the acquisition documentation (i.e., donation contracts and accession entries) was in order, but the objects were still waiting to be catalogued individually in the collection management system (CMS). At the time, the museum professionals working in the collections department had very little knowledge of the objects. When the collection was transferred to the museum in 2015 to wait for further assessment, the objects had labelling tags attached and had been given museum identification numbers. The donor party had prepared an Excel sheet that detailed each of the objects: Name, type, speed, standard protocol and in some cases, years of manufacture. In addition, the sheet had some rather odd nicknames for certain modems, such as "The Frog" and "The Farmer Modem", without further explanation.

First of all, the museum professionals felt the need to fill the gaps considering the years of manufacture, and acquire more knowledge about the technical terminology that was self-evident for engineers but not for professionals with a background from museum studies. The manuals received with the collection could have been studied following data transfer into object records in CMS, but how were they to find relevant information in the manuals? How well would the museum's cataloguing system be suited for this kind of data entry and would anyone benefit from such copying? The need for more in-depth information about the collection, beyond technical data, was evident. Thus, instead of using manuals as the primary source of information, it was decided to reach out to the community that was familiar with the topic in a variety of ways and invite members of the "modem community" to participate in Data Communications workshops coordinated and run by the Project Researcher (author) and Head of Collections at the Museum of Technology.

\subsection{Workshop Participants and Their Background}

Contacts made during the donation process proved to be useful. It also turned out that the reunion group that had visited the museum had on their own accord formed a "Museum Task Force", whose mission was to build a family tree of the Nokia modems and collect memories from the working life of those involved. The project team found this surprising and inspiring, and with the help of the contact persons, the first workshops were swiftly arranged.

The workshops arranged at the museum are recorded discussions inspired by the collection objects. The total number of workshops is yet to be settled, but the estimation is that within the scope of the project, 5-10 workshops will be arranged and the total number of participants will be approximately 10-20 during 2018-2019. Participants are invited to the museum in small groups of two or three and individually. In both cases, the program outline is the same, requiring three hours of engagement, including a preliminary questionnaire online and a workshop discussion at the museum.

All the participants have in common a long work history at the Nokia Data Communications department. The average education of a workshop participant is engineer, although there is variance in the field and level of studies. Many participants are still working (some currently work for Nokia), while some are retired. The participants' personal experiences related to the modems cover the whole timeline of the collection, including the early devices from the end of the 1960s. 


\subsection{Cataloguing Assistance or Something Else?}

I will now return to the planning of the project. It was assumed that through testimonials from professionals who have developed and marketed the objects, museum professionals and audiences could achieve a better understanding of the collection, instead of seeing the ninety devices in it as "grey boxes". The documentation project was not connected to any ongoing exhibition project, but after the documentation, the potential for further use of the collection was expected to increase. How would the gathered knowledge be shared? Are the outcomes of the documentation workshops directed mainly for the use of museum staff and researchers or for a wider audience? Should the project concentrate on enriching the data in CMS? What are the options?

It was agreed that the objects would be catalogued in CMS and some of the data would be published in the public database. The collections management system of the Museum of Technology has an interface with Finna (www.finna.fi), which is a collection of search services providing free access to material from Finnish museums, libraries, and archives. It also has a shared user interface for museums (museot.finna.fi). One option was to tie the workshops to the systematic cataloguing of ninety objects, thus enriching the contextual information in CMS records, object by object. However, this idea was abandoned.

The main disadvantage of the systematic cataloguing approach is that a significant part of the information that was found interesting is unsuited for individual object records in CMS. In the record, there is an entry for the use and function of the object, yet apart from simple ontological keywords, there are no consistent and practical ways of adding data that connects and groups the objects with multiple and overlapping storylines of innovations and product development. This kind of information has no place in CMS, because it falls between the individual object records.

Besides other concerns, the cataloguing approach is not an essential starting point for collaboration. After all, it was important to find a way that would inspire former Nokia Data Communication employees to contribute to the documentation project in their free time. The enthusiasm visible in the reunion would have been easy to kill with formal and potentially boring cataloguing object by object, repeated ninety times. The cataloguing approach would also require timely-commitment, which those still working just do not have. All in all, there was a need to come up with a participative documentation method that would be efficient and inspiring.

Instead of strict structured go-through-device-after-device, it was decided to embrace the unpredictable. Rather than looking for someone who was willing to commit to the project, the project team wanted to give a chance of less-demanding participation to as many as possible. Informal discussion was assumed as a good starting point and it was also assumed that multiple points of view would complement each other. In short, the aim was to study which devices were considered to be most relevant and collect the stories evoked. The cataloguing task of the collection will be carried out by museum professionals.

\subsection{Do We Unintentionally Create Biased Information?}

The hypothesis, now proved correct, was that interesting testimonials about the objects would be gained as a result of workshop discussions. However, because there are close to a hundred individual objects in the collection and the timeline spans over six decades, it had to be assumed that not all objects would invoke memories and that the information gained would not be solid. Even if the museum professionals participating in the project hoped to gain an understanding of "key artefacts" in the collection, it was also understood that the results would be, to some extent, dependent on workshop participants.

For the museum staff, who made the decision to acquire the Nokia Data Communications collection, every object is important. The idea was to preserve a comprehensive series of Nokia products and it was considered that as a collection, the objects also tell something about the community that collected it. With the choice of preserving the collection as a sub collection, the decision-makers suggested that it should be considered as an entity in the future as well. Even if some of the modems 
do not inspire recollections in the workshops, their standing in the collection remains unchallenged. However, the future of the collection is yet not known. If the workshop discussions are deconstructed to individual object records in CMS, would it create a far-reaching value classification? Will the researcher in the future wonder about the number of modems in the collections and deem valuable only those that have some additional information on CMS records? Is deconstructing information into ninety records possible at all or would the pieces of discussions seem just as random notes without tangible relevance?

From the 1960s to the 2010s, thousands of people possibly worked with the modems in Nokia Data Communications. The invitation to the workshops reached only a select group, and only 10-20 persons will be interviewed. There is no need to question the qualifications of the informants, yet if the information is added in the object records, will testimonials of a small group be given too great a weight? The points of view in the workshops have been on product development and marketing of the modems, and all participants are engineers. How about the views of other employees, for example those working in the assembly line? There are even wider considerations: How about the customers of Nokia who used the devices or the technicians who installed them? Whose opinions and views matter when documenting the devices of serial production?

Although just a small anecdote, the following story about the nicknames related to the devices reflects the issue addressed above. In the visitor survey placed in the museum lobby, a visitor shared a personal memory of a modem from the early 1980s: "The big one was called "Big piggy" (Fin: Iso Possu) by technicians of Tele." Tele was at the time a Finnish Telecommunications operator that ordered modems from Nokia and was responsible for the installation of data communication systems, for example, in bank offices. However, in workshops, almost all Nokia engineers called the same device in white casing with the nickname "Big Blonde" (Fin: Iso Vaalee) spontaneously without hearing the comments of other participants. This nickname derives from a Finnish movie and book and refers to a mysterious woman who the protagonist among others is trying to conquer. The device Nokia engineers "conquered" is the first commercial DSP application by Nokia and was named a key artefact of the collection by several workshop participants. Moreover, one of the workshop participants called the device in question "the father of the DSP-technology" and due to its size and weight, it has also been called "Elephant modem" [7]—yet "Big piggy" lacks in Nokian vocabulary.

\section{Significance Assessment as the Key}

The challenges described convinced the project team that object cataloguing in CMS is not the ideal platform for the detailed information gained in the workshops. Cataloguing level is better suited for classification and facts that can be agreed on, rather than for multifaceted workshop testimonials that sometimes have only vague connection with singular artefacts. It was agreed upon, that rather minimal information on the excel sheet received with the donation was after all close to the ideal level of information in the cataloguing. In addition, images of the objects, measurements, general description and a few ontological keywords will be added by the museum professionals. Multi-dimensional and partly subjective level of knowledge that was accumulated in the workshops will be preserved in the digital and manual archive for further research. Documentation of the workshops kept in the archive include the project report, video and audio recordings of the workshop discussions and information on the participants (i.e. answers in preliminary online survey).

Nevertheless, something was missing. How was the knowledge the project team gained in the workshops to be shared? As a solution, it was decided to use the significance assessment method that was introduced in the Australian publication, Significance 2.0 [1]. In this documentation project, the team applied mainly the Finnish publication Merkitysanalyysimenetelmä ${ }^{1}$ [2], that is, as stated

1 The English version of Merkitysanalyysimenetelmä, Analysing Significance (Häyhä, Jantunen \& Paaskoski), was published in January 2019 and is available online at https: / /icomfinland.fi/ (accessed on 5 February 2019). This paper was originally 
by its authors Häyhä, Jantunen and Paaskoski, an adaptation based on Significance 2.0 and other international publications [2] (p. 5). The reason for primarily applying the Finnish adaption of the method in the project was a practical one-the Museum of Technology was one of the pilot museums testing it in practice in 2015, and therefore staff of the museum's collection department already had experience on using it. Merkitysanalyysimenetelmä was considered as an ideal tool, containing a compact and explicit, yet adjustable procedure that is easy to carry out in practice.

Significance assessment can be described as a study done by using fixed criteria as the basis. It can be done for a single object or a collection and is also applicable for cross-collection projects [1] (p. 1). In both publications, the process starts with researching and analyzing the chosen object (than can be for example an individual museum object or a collection), and results in better understanding of its value. The findings are summarised in a Statement of Significance [1] (p. 10), [2] (pp. 10-13). In Significance 2.0, the criteria include four primary values (historic; artistic or aesthetic; scientific or research potential; social or spiritual) and four modifiers of the main criteria (provenance; rarity or representativeness; condition or completeness; and interpretive capacity) [1] (p. 10). Even if the Finnish adaption [2] shares the same core concept as the Australian publication [1], there are differences in work flow, assessment criteria, and outcomes of the assessment suggested. The criteria applied in the Finnish version is representativeness, authenticity, historic and cultural significance, significance related to the experience, social significance, ideal state, and usability (translation from Finnish by the author) [2] (pp. 12-13).

Significance assessment turned out to be the key in the documentation project of the Nokia Data communications collection in three ways: (1) The outcomes of significance assessment form a distinct level of knowledge supplementing the cataloguing information; (2) Statement of Significance is a link between the workshop discussions and cataloguing information; and (3) publications on significance assessment $[1,2]$ offered beneficial tools to create a functional yet adjustable framework for workshop discussions. I will now discuss these three points in detail.

\subsection{Significance Assessment as A Level of Knowledge}

Significance assessment is not cataloguing, but a transparent and collaborative process that goes further in "building on the catalogue description with additional steps that establish the meaning and values of the item, drawing conclusions about its importance" [1] (p. 14). In the Australian publication, significance assessment is described to be: "the process of researching and understanding the meanings and values of items and collections. The assessment process explores all the elements that contribute to meaning, including history, context, provenance, related places, memories, and comparative knowledge of similar items. It goes beyond a conventional catalogue description to explain why and how the item is important and what it means" [1] (p. 10).

Following the recommendations of Häyhä, Jantunen and Paaskoski [2], two documents are prepared as an outcome of the assessment of Nokia Data Communications collection: a detailed Study on Significance marked with references and intended for internal use and a summarizing Statement of Significance that is public (translations from Finnish by the author). The recorded workshop discussions inspired by the modems are used as research material. In the public statement is stated among other things: "Why and how the subject is significant and how significance add to the usability" [2] (p. 13). The information about the writers of the documents and all parties involved in the significance assessment is also included in both outcomes. The Statement of Significance is dated so it can be distinguished from previous and future interpretations. Although it is a summary, it can also include essential sources used in the assessment [2] (p. 13). In the case of studying Nokia modems,

prepared for ICOM International Council of Museums CIDOC (International Committee of Documentation) Conference in 2018 and therefore contains terms from the Finnish publication [2] translated by the author. 
the assessment process involves both the workshops and the following analysis of the discussions within the Study on Significance and Statement of Significance.

The significance method was used in the Museum of Technology previously a few years ago for the assessment of the collection of inventor Eric Tigerstedt [8]. Also in the current project, the aim is to assess the collection as a whole, instead of assessing the significance of each individual object. It is the ideal approach, as the project has a focus on the chains of product development, innovations, and how people who have worked with the modems see them in relation to one another. Significance assessment allows to explain multiple levels of significance throughout the collection but also allows focusing on individual objects or small groups of objects. The statement and the study can also refer outside the actual collection, linking the devices in the collection to technological systems, other R\&D that has been done in Nokia or memories of working life in Nokia.

Furthermore, significance assessment is a well-suited way of stating in public the choices that were made during the process. This includes the choices that the project team made in planning and implementing the workshops, but also the choices made in the acquisition of the collection (i.e., why it was decided to accept the whole collection, instead of choosing only a few objects). It is also the suitable place for explaining why the assessment in question was based primarily on testimonials of Nokia engineers. Häyhä, Paaskoski and Jantunen have stated that it is important to make visible the persons assigning the significance, because collections can be meaningful and significant in a variety of ways depending on the background, values, knowledge, and understanding. All this influences the result [2] (p. 9). Evaluators of significance are both the Nokia engineers who take part in the workshops and the museum professionals who determine the framework of the project and write the Study on Significance and Statement of Significance. Thus, it can be argued that the right for interpretation is claimed through transparency. Discussing choices tie the results of the assessment to the provenance of knowledge. For instance, it is more justifiable to name key artefacts of the collection in the study that is written as the conclusion of the workshops, when the starting points of the evaluation have been stated transparently.

\subsection{Statement of Significance as a Link}

Even if significance assessment is not cataloguing, Häyhä, Jantunen and Paaskoski [2] (p. 13) suggest that the Statement of Significance can be attached on the record of the object in CMS. In the case of the Nokia Data Communications Collection, every individual object record of the collection will have at least a note about the assessment that took place in 2018-2019 and references to Study on Significance (for internal use) and Statement of Significance (for public use). It is also possible to add a link to the latter. The study and the statement include information on some individual objects in the collection and they are always stated with their museum identification number. It is the permanent identifier of the object that does not change, even if the model number in CMS is later found to be erroneous and corrected. By doing this, the assessment is also more clearly connected with the objects of the museum collection.

The Study on Significance and the Statement of Significance are important links between rather minimal catalogue information in CMS and the workshops documentation kept in the collection archives. The outcomes of the assessment (i.e. the study and the statement) can be utilised in many ways. In a way, both these documents can be seen as teasers for studying the collection. The wider Study on Significance (for internal use only) offers the museum staff and researchers an overview of the collection and of the workshop documentation and thus enhances their potential use. The public Statement of Significance can be used in the many channels the museum has to relay information of museum collections to wider audiences. With the statement, the information about the ninety modems in the public database Finna.fi also starts to make more sense.

The key point is that the result of the assessment is not a final evaluation, but parallel—conflicting evaluations are possible and new interpretations are expected in time [2] (p. 9). This means that the 
objects in the collection and their catalogue information can be used in a multitude of evaluations in which results rely on the method, participants, and their point of view.

\subsection{Significance Assessment Checklists as a Tool}

In practicality, the workshop discussions are unstructured interviews. The Project Researcher and Head of Collections have made a prearranged set of the questions but no strict plan for workshops, as the aim is to keep the atmosphere in the workshops informal. However, some structure is needed to aid the conversation and naturally some predetermined questions are open: Are all the objects in the collection random examples of modem models or are there unique items for example prototypes that we not in production? How was the collection formed? In what kind of quantities were the modems manufactured and who were the most important customers of Nokia Data Communications?

The key question in the workshops are: What objects in the collection are (in your opinion) particularly significant and why? (The participants are asked to choose five objects and this key question is presented also in advance in the online survey with a list of objects). After this, the participants are also asked to point out five devices they themselves felt most essential in their career. This enables us to study if the choices in two questions would be the same.

Publications on significance assessment [1,2] offer criteria-bound checklist questions that can be used regardless of the type of the collection in question. Examples of questions in Significance 2.0 are: "Does it have unusual qualities that distinguish it from other items in the class or category?", "Does it have a special place in the collection in relation to other items or a collection theme?", "Is it associated with a particular person, group, event, place or activity and how is this important?" [1] (p. 40). In the data communication workshops, the questions applied are mainly the ones presented in the Finnish publication [2]. The project team did not choose every one of them, but rather compared them with their own set of questions and included some of them, partly modified. By doing so, the aim was to ensure that all the criteria of the significance assessment is discussed during the workshops so that execution of the Study on Significance is possible. The questions are also adjusted for each workshop with the information the participants give in the preliminary online survey about their careers and how the work involved the modems in question.

\section{Workshops in Action}

This chapter discusses an overview of the workshop and some aspects and experiences of the workshops in action. A workshop includes a preliminary online survey, a short introduction, and a workshop discussion at the museum. The idea is to detail arrangements to help trace the provenance of information after the workshops.

"Photo Elicitation" (also known as "Photo Interview") was found helpful in planning the workshops. The method has become popular in social and historical research [3] (p. 173). Tinkler shows how photo elicitation has been used, evaluating its main benefits and offering practical strategies in making use of the method [3]. Tinkler's and Harper's [3,4] views on photo elicitation inspired us in planning the workshops closely connected with the objects. In the literature, it was hypothesized that touching the pictures invoked more memories than mere looking, and this was taken into consideration. In the data communication workshops, the method was applied from $2 \mathrm{D}$ to $3 \mathrm{D}$, turning photo elicitation into sc. object elicitation. Special consideration was given to the notes about the practical arrangements that deal with group formation and ways to document the workshops. Observations of the method in practice also indicated that pictures do not always produce expected discussion [3] (pp. 175-178), [4] (pp. 175-178). This was one of the reasons why it was decided to arrange several workshops to ensure as full a picture as possible.

An advantage of photo elicitation is in the role of the picture as a facilitator. Photographs can serve as icebreakers, stimulants of memory, and can encourage people to talk [3] (p. 173, 186). Experience in working with museum collections have shown that artefacts have those same qualities. The donors of objects are often interviewed during the donation process and it has been noticed that once the 
objects are present, the atmosphere relaxes as the objects feed the dialogue. For this reason, it was decided to keep the collection in focus as an essential part of the workshop discussions. In theory, the discussions about the significance of the collection could have been carried out without objects or with pictures or list of the objects. However, there was a will to keep the collection in full view of the participants during the discussions and also create easy access to the objects so that they could be handled, if necessary.

\subsection{Introduction for the Workshop}

Every workshop starts with a short introduction before the recording of the discussion starts. The interest to find the key artefacts is emphasized and the participants are encouraged to focus on the devices they consider important. The idea is not to go through each individual object. The participants are reminded that the devices can be seen as technological objects and also as a part of an innovation chain or as industrial, every day or design objects. In addition, personal career memories can be relevant, whether they would be about marketing, technological standards, hardware, or software design.

In the introduction, the workshop participants are also shown the questions and some of the results gained from the simple survey for the museum visitors. In the survey, the visitors were asked to share their thoughts, questions or memories that two example modems of the collection evoked. The devices were placed in a showcase without name, production time or other contextual information. In their answers, visitors ponder about technological gadgets getting smaller, the amazing speed of development, and change in the design. Some mention Nokia as a company. On the other hand, the answers reveal that about $1 / 3$ did not recognize the objects. This was to be expected because the collection consists mainly of devices that were not meant for consumer use. Answers in the survey also reflect that a lot of visitors of the museum are schoolchildren and families with kids. This viewpoint is raised to emphasize the wish that the workshop discussion generates information that would prove useful and valuable in sharing knowledge for the larger public, not just details about the technology and product development for experts in the field. However, there is no need to limit the scope of the discussion. Nokia heritage is vital to document and this documentation entails an approach to the devices that is natural and familiar to the engineers.

Before heading to the objects, two rules are set. Rule 1: touching the objects is allowed; and Rule 2: when referring to the objects, one should use the museum identification number attached to it. Although the collection is in the premises of the museum, it has not been thoroughly catalogued and musealised. The people who come from the community that collected and preserved the objects can be trusted to touch and handle the objects in the workshop. In some cases, removal of the protective case has been necessary to view some details in the modem.

Reasons to introduce the use of cataloguing number are twofold. First, there is an aim to make museum practises visible, by telling how an object becomes a museum object. Second, and the most important reason is the need for clear identicfication number, which enables keeping a track of which specific object is in discussion. This is important, as the devices and their parts have several product codes, in addition to the names used in marketing and even nicknames. The identification number of each museum object is unambiguous and remains the same since the registration of the object. Recordings of the workshop (audio, video files) can also be indexed with the object identification numbers, marking sections with explicit information about a specific object.

The decision to video the workshops was done to help with the processes that followed the workshops. Audio and video recordings of the workshop are preserved in the museum archive for later use in the project and also for further research. During the introduction, reasons for the recording are explained and it is specifically mentioned that audio and video are not for use as such in exhibitions. This seems to make it easier for everyone concerned. The atmosphere during the discussions is informal and there is no need for fancy equipment or professional technical support in recording the workshops. The participants sign a consent form for the recording and for archiving the 
personal information they have given in the preliminary online survey. In the survey, the participants are asked about their studies and work history; yet, the questionnaire allows personal choice in how much information the participant is willing to share.

\subsection{Experiences of the Workshop Discussions}

After the introduction, the participants are guided to the workspace where the objects are displayed and the recording of the discussion starts. The Museum's Project Researcher and Head of Collections are present in the workshops, recording the session and presenting questions. Each workshop has 1-3 participants. Small groups allow enough time for the point of view of each participant. The small group size also make it easier to review the recording, as there is not so much overlapping speech that would hinder understanding what was said.

Since the background information of the participants is given in the online survey, it is possible to move on to discussion about the key artefacts quite quickly. The objects are laid out in the workspace so that the participants can view them all easily and the possible handling of the objects is also made easy. The objects are clearly labelled with numbers (1-90). The number indicates the two last digits of the museum identification number of the objects. Participants follow a rule about talking about the objects by their museum identification number quite well. The museum staff can also clarify which object number is in discussion, if the participant just points towards an object or refers to its product code. The modems the participants chose in the online survey to be the most important in the whole collection and most relevant in their own careers are tagged with signs in advance. However, the discussion is not limited to the pre-selected objects.

Although the project is still ongoing, the project team is convinced to have chosen the right method for the documentation. The workshop participants seem content, the framework of the workshops seems to work, and a lot of new and useful information about the collection is gathered. Such as the fact that the knowledge on the modems was utilised in designing mobile phones using GSM protocol and what kind of expertise Nokia received from the United States in product development. Personal career memories are also recorded. For instance, a story about how to close a deal with an important client successfully, even if told he does not like "the bathroom scale" (referring to the new flat design of the product). Nevertheless, the modems are products of serial manufacture, "I made this" is a comment that is heard at times.

In practice, the workshops have all been very different. Although in the introduction, it is reminded that technical product development is not the sole focus or even the most important focus, some participants have felt the need to go through the modems one by one, chronicling the technical specifications in detail. In some way, this resembles certain observations in photo elicitation: The objects do not always help with focus and personal objects may excite interviewees to pursue their own agendas beyond the task [3] (p. 175). However, since there is opportunity to arrange multiple workshops, different viewpoints have successfully complemented each other. Some participants are orientated towards the technical detail, some more on the bigger picture, and some share personal memories from their careers. In private interviews, there is a possibility to focus more on the individual experience, but in a group discussion the advantage has been that conversation among peers brings out questions and points of view that the museum professionals could not have prepared for in advance.

Having several workshops instead of just one give a better chance to eliminate some of the randomness in the choice of key objects. While more detailed analysis is yet to be done, some conclusions can be made. The participants seem to emphasize as key objects the same devices they have personally worked on during their careers. The result and contributing factors can be discussed in more detail in the Study on Significance. To transfer this kind of biased information to the object catalogue could, however, present difficulties and lead to wrong conclusions.

Workshop participants have pointed out that a couple of important modem models are still lacking in the collection. Although the collection is non-accumulating, it has been agreed that acquisition of devices is still possible, if there is an agreement on the merit of the objects. It is likely that the gaps in 
the collection would not have been noticed without the close inspection and comparison of the objects that was possible during the workshops.

Some of the participants have directly or indirectly made their views known about how the collection should be presented in the museum and what an exhibition about modems should tell. This has been interesting because during the documentation process museum professionals have not made any reference to an exhibition, as it is not the goal of the documentation project. However, the assumption about displaying all donated objects is quite common in donation situations. Furthermore, the way the devices were laid out may have suggested this. For the workshop, the modems were brought to a workspace that had direct visual access to the exhibition.

Personal visions about the modem exhibition seem to influence what is brought out in the discussions. Exhibition visions often entail the assumption that the target audience would be other experts and that technical development, components and device architecture should be explored in great detail. Ideas about the texts and visual presentation are not easily reconciled with the need to engage with wider audiences. However, it seems that the idea of the modem exhibition might help participants process their thoughts and the information gained is helpful in classifications and in cataloguing the objects. Parts of the information irrelevant to the current significance assessment may still prove to be valuable for future research.

\section{Conclusions}

The strength of the documentation project discussed is in the combination of expertise and experiences of former Nokia employees and the documentation and interpretation skills of museum professionals. Views of the museum visitors were also learned from. The goal was to widen the perspective of the collection of all these three groups and it seems likely that the goal will be achieved.

Hence, with this experience, significance assessment can be recommended as a tool in planning documentation workshops for a variety of museum objects. Significance assessment offers a good, transparent framework, even for the documentation of industrially manufactured devices when first-hand knowledge is available from multiple sources. In the current documentation project, the chosen starting point was the testimonials of Nokia engineers. I have stated in this paper that significance assessment works in three ways: As a link, as a tool, and as a level of knowledge. I also suggest that collection objects in 3D work better in stimulating conversations than lists or pictures of the objects. The object-based documentation, sc. Object Elicitation, which was implemented in the workshops and inspired by studies on Photo Elicitation, is a productive way of dealing with a larger set of objects. The method facilitates a multifaceted discussion about technical devices, as long as a suitable partner is found.

Simple workshops are well suited for participatory work, especially when there is a desire to elicit multiple viewpoints and when participants cannot commit to long-term work with the museum. In the case of data communications workshops, the participants were given the option to share their memories without a strict framework while they were also familiarized with how a museum operates. Aside from the valuable workshop recordings and the information in them, as a result of the workshops, the museum now has a reserve of experts on the Nokia Data Communications collection and collaboration will continue in new ways. For the museum professionals and Nokia engineers, getting to know one another has made contacting more natural and easier, and there are ongoing discussions on adding a couple of devices to the collection. Exhibiting the whole collection has not been planned, but with the added information, the collection will be more useful for exhibitions and pedagogical programs. In the short term, with the new information gained in the workshops, the guides will have more background information about a couple of modems currently on display in the permanent exhibition

Did the project progress from Discussion to Catalogue as the title implies? Yes and No. After consideration, it was decided not to transfer detailed content from the workshop discussions to the collections management system, since it would be too fragmentary if divided on individual 
object records and might create misleading value classification. However, Study on Significance and Statement of Significance work well as a level of interpretation and function as a bridge that links cataloguing data in CMS with the documentation of workshop discussions kept in the collections archive. Arguably, if working with similar objects or collections, it can be beneficial to keep the catalogue information of individual objects concise and free of interpretation, yet accumulate and share additional knowledge with significance assessment. This is based on the idea that the result of the assessment is not final-parallel and conflicting views are possible and new interpretations can be expected [2] (p. 9). The significance assessment helps presenting the provenance of knowledge and leaves room for further assessments.

Funding: This project was funded by The Jenny and Antti Wihuri Foundation, 9 October 2017.

Acknowledgments: For collegial support in the project Riina Linna, MA, Producer, Museum of Technology; Marjo Mikkola, M.Sc.(Econ.), Museum Director, Museum of Technology; Kirsi Ojala, Lic.Phil., Head of Collections, Museum of Technology; Eeva Siltala, MA, Curator, Museum of Technology; Johanna Vähäpesola, MA, Head of Exhibitions and Learning, Museum of Technology.

Conflicts of Interest: The authors declare no conflict of interest. The funders had no role in the design of the study; in the collection, analyses, or interpretation of data; in the writing of the manuscript, or in the decision to publish the results.

\section{References}

1. Russell, R.; Winkworth, K. Signifigance 2.0. A guide to assessing the signifigance of collections. Collections Council of Australia Ltd. 2009. Available online: https://www.arts.gov.au/sites/g/files/net1761/f/ significance-2.0.pdf (accessed on 10 August 2018).

2. Häyhä, H.; Jantunen, S.; Paaskoski, L. Merkitysanalyysimenetelmä. Publications of Finnish Museum Association No. 64. Finnish Museum Association. 2015. Available online: http://www.museoliitto. fi/doc/Merkitysanalyysimenetelma1.pdf (accessed on 10 August 2018).

3. Tinkler, P. Using Photographs in Social and Historical Research; SAGE Publication Ltd.: London, UK, 2013.

4. Harper, D. Talking about pictures: A case for photo elicitation. Vis. Stud. 2002, 17, 13-26. [CrossRef]

5. Holm, Y. Haku Päällä. In Johdossa. Customer Magazine of Nokia Data Communications; Nokia Datasiirto: Helsinki, Finland, 1989; Volume 2, p. 8.

6. ICOM Code of Ethics for Museums. 2017. Available online: https://icom.museum/wp-content/uploads/ 2018/07/ICOM-code-En-web.pdf (accessed on 5 February 2019).

7. Koskinen, I. A Legendary Modem Takes the Final Bow. In Channel. International Customer Magazine of Nokia Data Communications; Nokia Data Communications: Helsinki, Finland, 1990; pp. 12-13.

8. Pietarinen, P. Uniikki Eric Tigerstedt. In Merkitysanalyysimenetelmä; Publications of Finnish Museum Association No. 64. Finnish Museum Association; 2015; pp. 36-38. Available online: http:/ / www.museoliitto. fi/doc/Merkitysanalyysimenetelma1.pdf (accessed on 10 August 2018).

(C) 2019 by the author. Licensee MDPI, Basel, Switzerland. This article is an open access article distributed under the terms and conditions of the Creative Commons Attribution (CC BY) license (http://creativecommons.org/licenses/by/4.0/). 